\title{
Fekete-Szegö Inequalities for Certain Classes of Biunivalent Functions
}

\author{
Şahsene Altınkaya and Sibel Yalçın \\ Department of Mathematics, Faculty of Arts and Science, Uludag University, Bursa, Turkey \\ Correspondence should be addressed to Şahsene Altınkaya; sahsenealtinkaya@gmail.com
}

Received 23 June 2014; Accepted 3 September 2014; Published 9 November 2014

Academic Editor: Cédric Join

Copyright (C) 2014 Ş. Altınkaya and S. Yalçın. This is an open access article distributed under the Creative Commons Attribution License, which permits unrestricted use, distribution, and reproduction in any medium, provided the original work is properly cited.

We obtain the Fekete-Szegö inequalities for the classes $S_{S, \Sigma}^{*}(\alpha, \phi)$ and $\mathfrak{E}_{S, \Sigma}(\alpha, \phi)$ of biunivalent functions denoted by subordination. The results presented in this paper improve the recent work of Crisan (2013).

\section{Introduction and Definitions}

Let $A$ denote the class of analytic functions in the unit disk

$$
U=\{z \in \mathbb{C}:|z|<1\}
$$

that have the form

$$
f(z)=z+\sum_{n=2}^{\infty} a_{n} z^{n}
$$

Further, by $S$ we will denote the class of all functions in $A$ which are univalent in $U$.

The Koebe one-quarter theorem [1] states that the image of $U$ under every function $f$ from $S$ contains a disk of radius $1 / 4$. Thus every such univalent function has an inverse $f^{-1}$ which satisfies

$$
\begin{gathered}
f^{-1}(f(z))=z, \quad(z \in U), \\
f\left(f^{-1}(w)\right)=w, \quad\left(|w|<r_{0}(f), r_{0}(f) \geq \frac{1}{4}\right),
\end{gathered}
$$

where

$$
\begin{aligned}
f^{-1}(w)= & w-a_{2} w^{2}+\left(2 a_{2}^{2}-a_{3}\right) w^{3} \\
& -\left(5 a_{2}^{3}-5 a_{2} a_{3}+a_{4}\right) w^{4}+\cdots .
\end{aligned}
$$

A function $f(z) \in A$ is said to be biunivalent in $U$ if both $f(z)$ and $f^{-1}(z)$ are univalent in $U$. Let $\Sigma$ denote the class of biunivalent functions defined in the unit disk $U$.
If the functions $f$ and $g$ are analytic in $U$, then $f$ is said to be subordinate to $g$, written as

$$
f(z) \prec g(z), \quad(z \in U)
$$

if there exists a Schwarz function $w(z)$, analytic in $U$, with

$$
w(0)=0, \quad|w(z)|<1, \quad(z \in U)
$$

such that

$$
f(z)=g(w(z)), \quad(z \in U) .
$$

Lewin [2] studied the class of biunivalent functions, obtaining the bound 1.51 for modulus of the second coefficient $\left|a_{2}\right|$. Subsequently, Brannan and Clunie [3] conjectured that $\left|a_{2}\right| \leq \sqrt{2}$ for $f \in \Sigma$. Netanyahu [4] showed that $\max \left|a_{2}\right|=4 / 3$ if $f(z) \in \Sigma$. Brannan and Taha [5] introduced certain subclasses of the biunivalent function class $\Sigma$ similar to the familiar subclasses of univalent functions consisting of strongly starlike, starlike, and convex functions. They introduced bistarlike functions and obtained estimates on the initial coefficients. Bounds for the initial coefficients of several classes of functions were also investigated in [6-12]. The coefficient estimate problem for each of the following Taylor-Maclaurin coefficients $\left|a_{n}\right|$ for $n \in \mathbb{N} \backslash\{1,2\} ; \mathbb{N}=$ $\{1,2,3, \ldots\}$ is presumably still an open problem.

Let $\phi$ be an analytic and univalent function with positive real part in $U$ with $\phi(0)=1, \phi^{\prime}(0)>0$, and $\phi$ maps the unit disk $U$ onto a region starlike with respect to 1 and symmetric 
with respect to the real axis. Taylor's series expansion of such function is of the form

$$
\phi(z)=1+B_{1} z+B_{2} z^{2}+B_{3} z^{3}+\cdots,
$$

where all coefficients are real and $B_{1}>0$.

By $S^{*}(\phi)$ and $C(\phi)$ we denote the following classes of functions:

$$
\begin{gathered}
S^{*}(\phi)=\left\{f: f \in A, \frac{z f^{\prime}(z)}{f(z)} \prec \phi(z) ; z \in U\right\}, \\
C(\phi)=\left\{f: f \in A, 1+\frac{z f^{\prime \prime}(z)}{f^{\prime}(z)} \prec \phi(z) ; z \in U\right\} .
\end{gathered}
$$

The classes $S^{*}(\phi)$ and $C(\phi)$ are the extensions of classical sets of starlike and convex functions and in such a form were defined and studied by Ma and Minda [13]. They investigated growth and distortion properties of functions in $S^{*}(\phi)$ and $C(\phi)$ as well as Fekete-Szegö inequalities for $S^{*}(\phi)$ and $C(\phi)$. Their proof of Fekete-Szegö inequalities requires the univalence of $\phi$. Ali et al. [14] have investigated FeketeSzegö problems for various other classes and their proof does not require the univalence or starlikeness of $\phi$. So in this paper, we assume that $\phi$ has series expansion $\phi(z)=1+$ $B_{1} z+B_{2} z^{2}+\cdots, B_{1}, B_{2}$ are real, and $B_{1}>0$. A function $f$ is bistarlike of Ma-Minda type or biconvex of Ma-Minda type if both $f$ and $f^{-1}$ are, respectively, Ma-Minda starlike or convex. These classes are denoted, respectively, by $S_{\Sigma}^{*}(\phi)$ and $C_{\Sigma}(\phi)$ (see [15]).

In [16], Sakaguchi introduced the class $S_{S}^{*}$ of starlike functions with respect to symmetric points in $U$, consisting of functions $f \in A$ that satisfy the condition $\operatorname{Re}\left(z f^{\prime}(z) /(f(z)-\right.$ $f(-z)))>0, z \in U$. Similarly, in [17], Wang et al. introduced the class $C_{S}$ of convex functions with respect to symmetric points in $U$, consisting of functions $f \in A$ that satisfy the condition $\operatorname{Re}\left(\left(z f^{\prime}(z)\right)^{\prime} /\left(f^{\prime}(z)+f^{\prime}(-z)\right)\right)>0, z \in U$. In the style of Ma and Minda, Ravichandran (see [18]) defined the classes $S_{S}^{*}(\phi)$ and $C_{S}(\phi)$.

A function $f \in A$ is in the class $S_{S}^{*}(\phi)$ if

$$
\frac{2 z f^{\prime}(z)}{f(z)-f(-z)} \prec \phi(z), \quad z \in U,
$$

and in the class $C_{S}(\phi)$ if

$$
\frac{2\left(z f^{\prime}(z)\right)^{\prime}}{f^{\prime}(z)+f^{\prime}(-z)} \prec \phi(z), \quad z \in U .
$$

In this paper, motivated by the earlier work of Zaprawa [19], we obtain the Fekete-Szegö inequalities for the classes $S_{S, \Sigma}^{*}(\alpha, \phi)$ and $\mathfrak{E}_{S, \Sigma}(\alpha, \phi)$. These inequalities will result in bounds of the third coefficient which are, in some cases, better than these obtained in [7].

In order to derive our main results, we require the following lemma.
Lemma 1 (see [20]). If $p(z)=1+p_{1} z+p_{2} z^{2}+p_{3} z^{3}+\cdots$ is an analytic function in $U$ with positive real part, then

$$
\begin{gathered}
\left|p_{n}\right| \leq 2, \quad(n \in \mathbb{N}=\{1,2, \ldots\}), \\
\left|p_{2}-\frac{p_{1}^{2}}{2}\right| \leq 2-\frac{\left|p_{2}\right|^{2}}{2} .
\end{gathered}
$$

\section{Fekete-Szegö Inequalities for the Function Class $S_{S, \Sigma}^{*}(\alpha, \phi)$}

Definition 2 (see [7]). A function $f \in \Sigma$ is said to be in the class $S_{S, \Sigma}^{*}(\alpha, \phi)$ if the following subordination holds:

$$
\begin{gathered}
\frac{2\left[(1-\alpha) z f^{\prime}(z)+\alpha z\left(z f^{\prime}(z)\right)^{\prime}\right]}{(1-\alpha)(f(z)-f(-z))+\alpha z\left(f^{\prime}(z)+f^{\prime}(-z)\right)}<\phi(z), \\
\frac{2\left[(1-\alpha) w g^{\prime}(w)+\alpha w\left(w g^{\prime}(w)\right)^{\prime}\right]}{(1-\alpha)(g(w)-g(-w))+\alpha w\left(g^{\prime}(w)+g^{\prime}(-w)\right)}<\phi(w),
\end{gathered}
$$

where $g(w)=f^{-1}(w)$.

We note that, for $\alpha=0$, the class $S_{S, \Sigma}^{*}(\alpha, \phi)$ reduces to the class $S_{S}^{*}(\phi)$ introduced by Ravichandran [18].

Theorem 3. Let $f$ given by (2) be in the class $S_{S, \Sigma}^{*}(\alpha, \phi)$ and $\mu \in \mathbb{R}$. Then

$$
\begin{aligned}
& \left|a_{3}-\mu a_{2}^{2}\right| \\
& \leq\left\{\begin{array}{c}
\frac{B_{1}}{2(1+2 \alpha)} \\
|\mu-1| \\
\leq \frac{1}{1+2 \alpha}\left|1+2 \alpha+2(1+\alpha)^{2} \frac{\left(B_{1}-B_{2}\right)}{B_{1}^{2}}\right| \\
\frac{|1-\mu| B_{1}^{3}}{\left|2(1+2 \alpha) B_{1}^{2}+4(1+\alpha)^{2}\left(B_{1}-B_{2}\right)\right|} ; \\
|\mu-1| \quad \\
\geq \frac{1}{1+2 \alpha}\left|1+2 \alpha+2(1+\alpha)^{2} \frac{\left(B_{1}-B_{2}\right)}{B_{1}^{2}}\right| .
\end{array}\right.
\end{aligned}
$$

Let $f \in S_{S, \Sigma}^{*}(\alpha, \phi)$ and $g$ be the analytic extension of $f^{-1}$ to $U$. Then there exist two functions $u$ and $v$, analytic in $U$ 
with $u(0)=v(0)=0,|u(z)|<1,|v(w)|<1, z, w \in U$, such that

$$
\frac{2\left(z f^{\prime}(z)+\alpha z^{2} f^{\prime \prime}(z)\right)}{(1-\alpha)(f(z)-f(-z))+\alpha z\left(f^{\prime}(z)+f^{\prime}(-z)\right)}=\phi(u(z)),
$$

$(z \in U)$,

$$
\begin{aligned}
& \frac{2\left(w g^{\prime}(w)+\alpha w^{2} g^{\prime \prime}(w)\right)}{(1-\alpha)(g(w)-g(-w))+\alpha w\left(g^{\prime}(w)+g^{\prime}(-w)\right)} \\
& =\phi(v(w)), \quad(w \in U) .
\end{aligned}
$$

Next, define the functions $p$ and $q$ by

$$
\begin{gathered}
p(z)=\frac{1+u(z)}{1-u(z)}=1+p_{1} z+p_{2} z^{2}+\cdots, \\
q(w)=\frac{1+v(w)}{1-v(w)}=1+q_{1} w+q_{2} w^{2}+\cdots .
\end{gathered}
$$

Clearly, $\operatorname{Re} p(z)>0$ and $\operatorname{Re} q(w)>0$. From (16) one can derive

$$
\begin{aligned}
& u(z)=\frac{p(z)-1}{p(z)+1}=\frac{1}{2} p_{1} z+\frac{1}{2}\left(p_{2}-\frac{1}{2} p_{1}^{2}\right) z^{2}+\cdots, \\
& v(w)=\frac{q(w)-1}{q(w)+1}=\frac{1}{2} q_{1} w+\frac{1}{2}\left(q_{2}-\frac{1}{2} q_{1}^{2}\right) w^{2}+\cdots .
\end{aligned}
$$

Combining (8), (15), and (17),

$$
\begin{aligned}
& \frac{2\left(z f^{\prime}(z)+\alpha z^{2} f^{\prime \prime}(z)\right)}{(1-\alpha)(f(z)-f(-z))+\alpha z\left(f^{\prime}(z)+f^{\prime}(-z)\right)} \\
& =1+\frac{1}{2} B_{1} p_{1} z+\left(\frac{1}{4} B_{2} p_{1}^{2}+\frac{1}{2} B_{1}\left(p_{2}-\frac{1}{2} p_{1}^{2}\right)\right) z^{2}+\cdots, \\
& \frac{2\left(w g^{\prime}(w)+\alpha w^{2} g^{\prime \prime}(w)\right)}{(1-\alpha)(g(w)-g(-w))+\alpha w\left(g^{\prime}(w)+g^{\prime}(-w)\right)} \\
& =1+\frac{1}{2} B_{1} q_{1} w+\left(\frac{1}{4} B_{2} q_{1}^{2}+\frac{1}{2} B_{1}\left(q_{2}-\frac{1}{2} q_{1}^{2}\right)\right) w^{2}+\cdots .
\end{aligned}
$$

From (18), we deduce

$$
\begin{gathered}
2(1+\alpha) a_{2}=\frac{1}{2} B_{1} p_{1}, \\
2(1+2 \alpha) a_{3}=\frac{1}{4} B_{2} p_{1}^{2}+\frac{1}{2} B_{1}\left(p_{2}-\frac{1}{2} p_{1}^{2}\right),
\end{gathered}
$$

and

$$
\begin{gathered}
-2(1+\alpha) a_{2}=\frac{1}{2} B_{1} q_{1}, \\
2(1+2 \alpha)\left(2 a_{2}^{2}-a_{3}\right)=\frac{1}{4} B_{2} q_{1}^{2}+\frac{1}{2} B_{1}\left(q_{2}-\frac{1}{2} q_{1}^{2}\right) .
\end{gathered}
$$

From (19) and (21) we obtain

$$
p_{1}=-q_{1} .
$$

Subtracting (20) from (22) and applying (23) we have

$$
a_{3}=a_{2}^{2}+\frac{1}{8(1+2 \alpha)} B_{1}\left(p_{2}-q_{2}\right) .
$$

By adding (20) to (22), we get

$$
4(1+2 \alpha) a_{2}^{2}=\frac{1}{2} B_{1}\left(p_{2}+q_{2}\right)-\frac{1}{4}\left(B_{1}-B_{2}\right)\left(p_{1}^{2}+q_{1}^{2}\right) .
$$

Combining this with (19) and (21) leads to

$$
a_{2}^{2}=\frac{B_{1}^{3}\left(p_{2}+q_{2}\right)}{8\left[(1+2 \alpha) B_{1}^{2}+2(1+\alpha)^{2}\left(B_{1}-B_{2}\right)\right]} .
$$

From (24) and (26) it follows that

$$
\begin{aligned}
a_{3}-\mu a_{2}^{2}=B_{1}[ & \left(h(\mu)+\frac{1}{8(1+2 \alpha)}\right) p_{2} \\
& \left.+\left(h(\mu)-\frac{1}{8(1+2 \alpha)}\right) q_{2}\right],
\end{aligned}
$$

where

$$
h(\mu)=\frac{B_{1}^{2}(1-\mu)}{8\left[(1+2 \alpha) B_{1}^{2}+2(1+\alpha)^{2}\left(B_{1}-B_{2}\right)\right]} .
$$

Then, in view of (8) and (12), we conclude that

$$
\left|a_{3}-\mu a_{2}^{2}\right| \leq \begin{cases}\frac{B_{1}}{2(1+2 \alpha)}, & 0 \leq|h(\mu)| \leq \frac{1}{8(1+2 \alpha)}, \\ 4 B_{1}|h(\mu)|, & |h(\mu)| \geq \frac{1}{8(1+2 \alpha)} .\end{cases}
$$

Taking $\mu=1$ or $\mu=0$ we get the following.

Corollary 4. If $f \in S_{S, \Sigma}^{*}(\alpha, \phi)$ then

$$
\left|a_{3}-a_{2}^{2}\right| \leq \frac{B_{1}}{2(1+2 \alpha)} .
$$

Corollary 5. If $f \in S_{S, \Sigma}^{*}(\alpha, \phi)$ then

$$
\left|a_{3}\right| \leq\left\{\begin{array}{c}
\frac{B_{1}}{2(1+2 \alpha)} ; \\
\frac{B_{1}-B_{2}}{B_{1}^{2}} \in\left(-\infty,-\frac{1+2 \alpha}{(1+\alpha)^{2}}\right] \cup[0, \infty) \\
\frac{B_{1}^{3}}{\left|2(1+2 \alpha) B_{1}^{2}+4(1+\alpha)^{2}\left(B_{1}-B_{2}\right)\right|} ; \\
\frac{B_{1}-B_{2}}{B_{1}^{2}} \in\left[-\frac{1+2 \alpha}{(1+\alpha)^{2}},-\frac{1+2 \alpha}{2(1+\alpha)^{2}}\right) \\
\cup\left(-\frac{1+2 \alpha}{2(1+\alpha)^{2}}, 0\right] .
\end{array}\right.
$$


Corollary 6. If

$$
\phi(z)=\left(\frac{1+z}{1-z}\right)^{\beta}=1+2 \beta z+2 \beta^{2} z^{2}+\cdots, \quad(0<\beta \leq 1),
$$

then inequalities (30) and (31) become

$$
\left|a_{3}-a_{2}^{2}\right| \leq \frac{\beta}{1+2 \alpha}, \quad\left|a_{3}\right| \leq \frac{\beta}{1+2 \alpha} .
$$

\section{Corollary 7. If}

$$
\begin{aligned}
\phi(z) & =\frac{1+(1-2 \beta) z}{1-z} \\
& =1+2(1-\beta) z+2(1-\beta) z^{2}+\cdots, \quad(0 \leq \beta<1),
\end{aligned}
$$

then inequalities (30) and (31) become

$$
\left|a_{3}-a_{2}^{2}\right| \leq \frac{1-\beta}{1+2 \alpha}, \quad\left|a_{3}\right| \leq \frac{1-\beta}{1+2 \alpha} .
$$

Remark 8. Corollaries 6 and 7 provide an improvement of the estimate $\left|a_{3}\right|$ obtained by Crisan [7].

\section{Fekete-Szegö Inequalities for the Function Class $\mathfrak{E}_{S, \Sigma}(\alpha, \phi)$}

Definition 9 (see [7]). A function $f \in \Sigma$ is said to be $\mathfrak{E}_{S, \Sigma}(\alpha, \phi)$ if the following subordination holds:

$$
\begin{gathered}
\left(\frac{2 z f^{\prime}(z)}{f(z)-f(-z)}\right)^{\alpha}\left(\frac{2\left(z f^{\prime}(z)\right)^{\prime}}{f^{\prime}(z)+f^{\prime}(-z)}\right)^{1-\alpha}<\phi(z), \\
\left(\frac{2 w g^{\prime}(w)}{g(w)-g(-w)}\right)^{\alpha}\left(\frac{2\left(w g^{\prime}(w)\right)^{\prime}}{g^{\prime}(w)+g^{\prime}(-w)}\right)^{1-\alpha}<\phi(w),
\end{gathered}
$$

where $g(w)=f^{-1}(w)$.

We note that, for $\alpha=0$, the class $\mathfrak{E}_{S, \Sigma}(\alpha, \phi)$ reduces to the class $C_{S}(\phi)$ introduced by Ravichandran [18].
Theorem 10. Let $f$ given by (2) be in the class $\mathfrak{E}_{S, \Sigma}(\alpha, \phi)$ and $\mu \in \mathbb{R}$. Then

$$
\begin{aligned}
& \left|a_{3}-\mu a_{2}^{2}\right| \\
& \leq\left\{\begin{array}{rl}
\frac{B_{1}}{2(3-2 \alpha)} ; & \\
|\mu-1| \leq & \frac{1}{3-2 \alpha} \\
& \times\left|3-3 \alpha+\alpha^{2}+2(2-\alpha)^{2} \frac{\left(B_{1}-B_{2}\right)}{B_{1}^{2}}\right| \\
\frac{|1-\mu| B_{1}^{3}}{\left|2\left(3-3 \alpha+\alpha^{2}\right) B_{1}^{2}+4(2-\alpha)^{2}\left(B_{1}-B_{2}\right)\right|} ; \\
|\mu-1| \geq & \frac{1}{3-2 \alpha} \\
& \times\left|3-3 \alpha+\alpha^{2}+2(2-\alpha)^{2} \frac{\left(B_{1}-B_{2}\right)}{B_{1}^{2}}\right|
\end{array} .\right.
\end{aligned}
$$

Let $f \in \mathfrak{E}_{S, \Sigma}(\alpha, \phi)$ and $g$ be the analytic extension of $f^{-1}$ to $U$. Then there exist two functions $u$ and $v$, analytic in $U$ with $u(0)=v(0)=0,|u(z)|<1,|v(w)|<1, z, w \in U$, such that

$$
\begin{aligned}
& \frac{2\left(z f^{\prime}(z)\right)^{\prime}}{f^{\prime}(z)+f^{\prime}(-z)}=\phi(u(z)), \\
& \frac{2\left(w g^{\prime}(w)\right)^{\prime}}{g^{\prime}(w)+g^{\prime}(-w)}=\phi(v(w)) .
\end{aligned}
$$

From (38), we deduce

$$
\begin{gathered}
2(2-\alpha) a_{2}=\frac{1}{2} B_{1} p_{1}, \\
2(3-2 \alpha) a_{3}-2 \alpha(1-\alpha) a_{2}^{2}=\frac{1}{4} B_{2} p_{1}^{2}+\frac{1}{2} B_{1}\left(p_{2}-\frac{1}{2} p_{1}^{2}\right),
\end{gathered}
$$

and

$$
\begin{gathered}
-2(2-\alpha) a_{2}=\frac{1}{2} B_{1} q_{1}, \\
2(3-2 \alpha)\left(2 a_{2}^{2}-a_{3}\right)-2 \alpha(1-\alpha) a_{2}^{2} \\
=\frac{1}{4} B_{2} q_{1}^{2}+\frac{1}{2} B_{1}\left(q_{2}-\frac{1}{2} q_{1}^{2}\right) .
\end{gathered}
$$

From (39) and (41) we obtain

$$
p_{1}=-q_{1} .
$$

Subtracting (40) from (42) and applying (43) we have

$$
a_{3}=a_{2}^{2}+\frac{1}{8(3-2 \alpha)} B_{1}\left(p_{2}-q_{2}\right) .
$$


By adding (40) to (42), we get

$$
4\left(3-3 \alpha+\alpha^{2}\right) a_{2}^{2}=\frac{1}{2} B_{1}\left(p_{2}+q_{2}\right)-\frac{1}{4}\left(B_{1}-B_{2}\right)\left(p_{1}^{2}+q_{1}^{2}\right) .
$$

Combining this with (39) and (41) leads to

$$
a_{2}^{2}=\frac{B_{1}^{3}\left(p_{2}+q_{2}\right)}{8\left[\left(3-3 \alpha+\alpha^{2}\right) B_{1}^{2}+2(2-\alpha)^{2}\left(B_{1}-B_{2}\right)\right]} .
$$

From (44) and (46) it follows that

$$
\begin{aligned}
a_{3}-\mu a_{2}^{2}=B_{1}[ & \left(h(\mu)+\frac{1}{8(3-2 \alpha)}\right) p_{2} \\
& \left.+\left(h(\mu)-\frac{1}{8(3-2 \alpha)}\right) q_{2}\right],
\end{aligned}
$$

where

$$
h(\mu)=\frac{B_{1}^{2}(1-\mu)}{8\left[\left(3-3 \alpha+\alpha^{2}\right) B_{1}^{2}+2(2-\alpha)^{2}\left(B_{1}-B_{2}\right)\right]} .
$$

Then, in view of (8) and (12), we conclude that

$$
\left|a_{3}-\mu a_{2}^{2}\right| \leq \begin{cases}\frac{B_{1}}{2(3-2 \alpha)}, & 0 \leq|h(\mu)| \leq \frac{1}{8(3-2 \alpha)} \\ 4 B_{1}|h(\mu)|, & |h(\mu)| \geq \frac{1}{8(3-2 \alpha)} .\end{cases}
$$

Taking $\mu=1$ or $\mu=0$ we get the following.

Corollary 11. If $f \in \mathfrak{E}_{S, \Sigma}(\alpha, \phi)$ then

$$
\left|a_{3}-a_{2}^{2}\right| \leq \frac{B_{1}}{2(3-2 \alpha)} \text {. }
$$

Corollary 12. If $f \in \mathfrak{E}_{S, \Sigma}(\alpha, \phi)$ then

$$
\left|a_{3}\right| \leq\left\{\begin{array}{c}
\frac{B_{1}}{2(3-2 \alpha)} ; \\
\frac{B_{1}-B_{2}}{B_{1}^{2}} \in\left[-\infty, \frac{\alpha-3}{2(2-\alpha)}\right] \\
\cup\left[\frac{\alpha(1-\alpha)}{2(2-\alpha)^{2}}, \infty\right) \\
\frac{B_{1}^{3}}{\left|2\left(3-3 \alpha+\alpha^{2}\right) B_{1}^{2}+4(2-\alpha)^{2}\left(B_{1}-B_{2}\right)\right|} ; \\
\frac{\alpha-3}{B_{1}-B_{2}} B_{1}^{2} \in\left[\frac{3 \alpha-\alpha^{2}-3}{2(2-\alpha)}\right) \\
\cup\left(\frac{3 \alpha-\alpha)^{2}-3}{2(2-\alpha)^{2}}, \frac{\alpha(1-\alpha)}{2(2-\alpha)^{2}}\right]
\end{array} .\right.
$$

Corollary 13. If

$$
\phi(z)=\left(\frac{1+z}{1-z}\right)^{\beta}=1+2 \beta z+2 \beta^{2} z^{2}+\cdots, \quad(0<\beta \leq 1),
$$

then inequalities (50) and (51) become

$$
\left|a_{3}-a_{2}^{2}\right| \leq \frac{\beta}{3-2 \alpha}, \quad\left|a_{3}\right| \leq \frac{\beta}{3-2 \alpha} .
$$

Corollary 14. If

$$
\begin{aligned}
\phi(z) & =\frac{1+(1-2 \beta) z}{1-z} \\
& =1+2(1-\beta) z+2(1-\beta) z^{2}+\cdots, \quad(0 \leq \beta<1),
\end{aligned}
$$

then inequalities (50) and (51) become

$$
\left|a_{3}-a_{2}^{2}\right| \leq \frac{1-\beta}{3-2 \alpha}, \quad\left|a_{3}\right| \leq \frac{1-\beta}{3-3 \alpha+\alpha^{2}} .
$$

Remark 15. Corollaries 13 and 14 provide an improvement of the estimate $\left|a_{3}\right|$ obtained by Crisan [7].

\section{Conflict of Interests}

The authors declare that there is no conflict of interests regarding the publication of this paper.

\section{References}

[1] P. L. Duren, Univalent Functions, vol. 259 of Grundlehren der Mathematischen Wissenschaften, Springer, New York, NY, USA, 1983.

[2] M. Lewin, "On a coefficient problem for bi-univalent functions," Proceedings of the American Mathematical Society, vol. 18, pp. 63-68, 1967.

[3] D. A. Brannan and J. G. Clunie, "Aspects of comtemporary complex analysis," in Proceedings of the NATO Advanced Study Instute Held at University of Durham: July 1-20, 1979, Academic Press, New York, NY, USA, 1980.

[4] E. Netanyahu, "The minimal distance of the image boundary from the orijin and the second coefficient of a univalent function in $|z|<1$," Archive for Rational Mechanics and Analysis, vol. 32, pp. 100-112, 1969.

[5] D. A. Brannan and T. S. Taha, "On some classes of bi-univalent functions," Studia Universitatis Babes-Bolyai Mathematica, vol. 31, no. 2, pp. 70-77, 1986.

[6] S. Altinkaya and S. Yalcin, "Initial coefficient bounds for a general class of biunivalent functions," International Journal of Analysis, vol. 2014, Article ID 867871, 4 pages, 2014.

[7] O. Crisan, "Coefficient estimates for certain subclasses of biunivalent functions," General Mathematics Notes, vol. 16, no. 2, pp. 93-102, 2013.

[8] B. A. Frasin and M. K. Aouf, "New subclasses of bi-univalent functions," Applied Mathematics Letters, vol. 24, no. 9, pp. 15691573, 2011.

[9] B. S. Keerthi and B. Raja, "Coefficient inequality for certain new subclasses of analytic bi-univalent functions," Theoretical Mathematics \& Applications, vol. 3, no. 1, pp. 1-10, 2013.

[10] N. Magesh and J. Yamini, "Coefficient bounds for certain subclasses of bi-univalent functions," International Mathematical Forum. Journal for Theory and Applications, vol. 8, no. 25-28, pp. 1337-1344, 2013. 
[11] H. M. Srivastava, A. K. Mishra, and P. Gochhayat, "Certain subclasses of analytic and bi-univalent functions," Applied Mathematics Letters, vol. 23, no. 10, pp. 1188-1192, 2010.

[12] Q. H. Xu, Y. C. Gui, and H. M. Srivastava, "Coefficient estimates for a certain subclass of analytic and bi-univalent functions," Applied Mathematics Letters, vol. 25, no. 6, pp. 990-994, 2012.

[13] W. C. Ma and D. Minda, "A unified treatment of some special classes of univalent functions," in Proceedings of the Conference on Complex Analysis (Tianjin, 1992), Conference on Proceedings Lecture Notes for Analysis, I, pp. 157-169, International Press, Cambridge, Mass, USA, 1994.

[14] R. M. Ali, V. Ravichandran, and N. Seenivasagan, "Coefficient bounds for $p$-valent functions," Applied Mathematics and Computation, vol. 187, no. 1, pp. 35-46, 2007.

[15] R. M. Ali, S. K. Lee, V. Ravichandran, and S. Supramanian, "Coefficient estimates for bi-univalent Ma-Minda starlike and convex functions," Applied Mathematics Letters, vol. 25, no. 3, pp. 344-351, 2012.

[16] K. Sakaguchi, "On a certain univalent mapping," Journal of the Mathematical Society of Japan, vol. 11, pp. 72-75, 1959.

[17] Z. G. Wang, C. Y. Gao, and S. M. Yuan, "On certain subclasses of close-to-convex and quasi-convex functions with respect to k-symmetric points," Journal of Mathematical Analysis and Applications, vol. 322, no. 1, pp. 97-106, 2006.

[18] V. Ravichandran, "Starlike and convex functions with respect to conjugate points," Acta Mathematica, vol. 20, no. 1, pp. 31-37, 2004.

[19] P. Zaprawa, "On the Fekete-Szegö problem for classes of bi-univalent functions," Bulletin of the Belgian Mathematical Society. Simon Stevin, vol. 21, no. 1, pp. 169-178, 2014.

[20] C. Pommerenke, Univalent Functions, Vandenhoeck \& Ruprecht, Göttingen, Germany, 1975. 


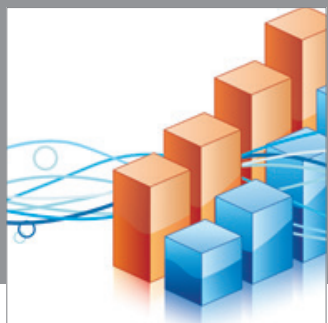

Advances in

Operations Research

mansans

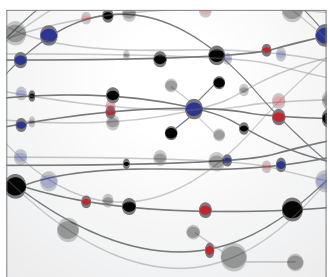

The Scientific World Journal
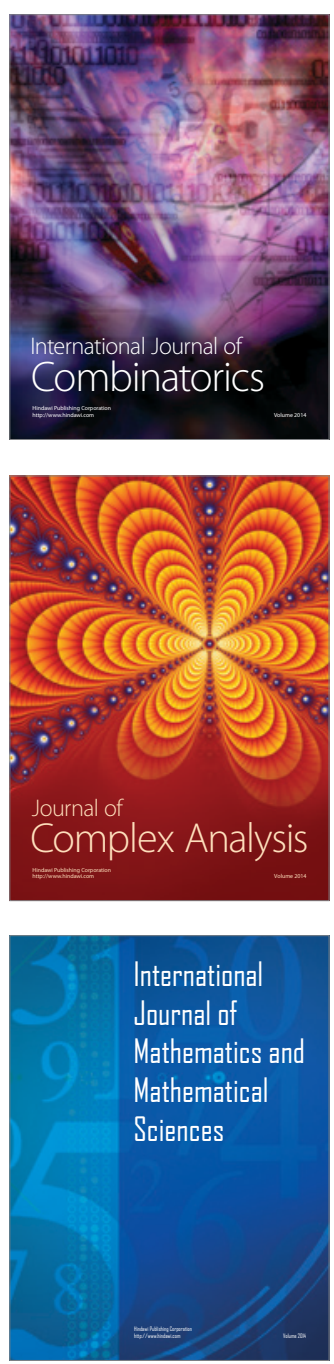
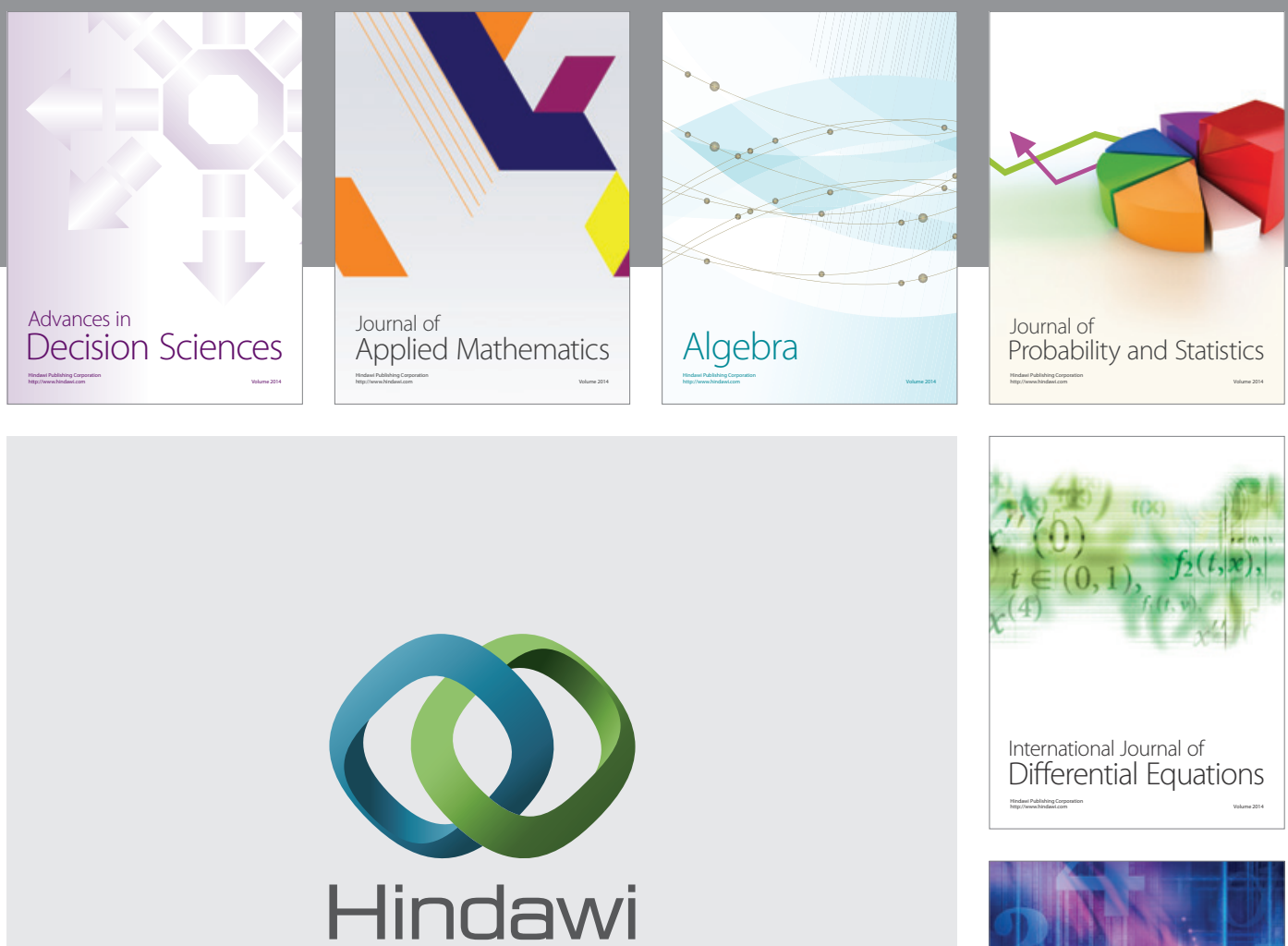

Submit your manuscripts at http://www.hindawi.com
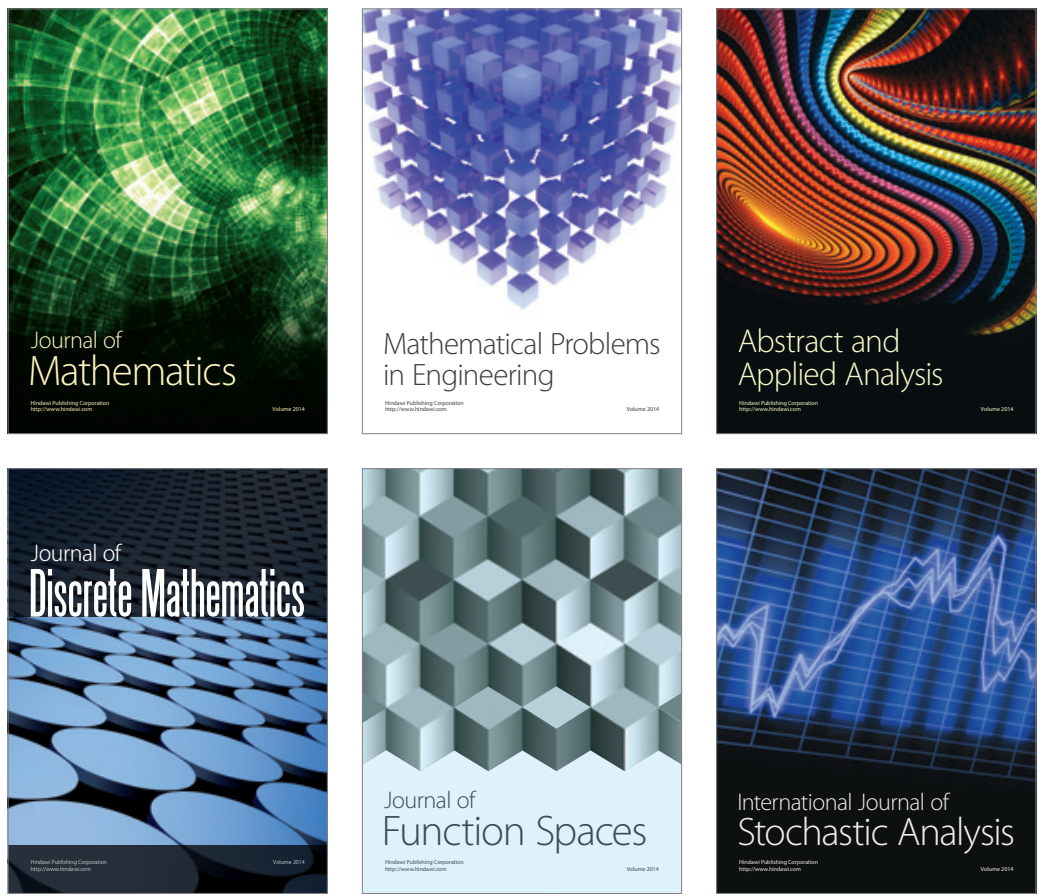

Journal of

Function Spaces

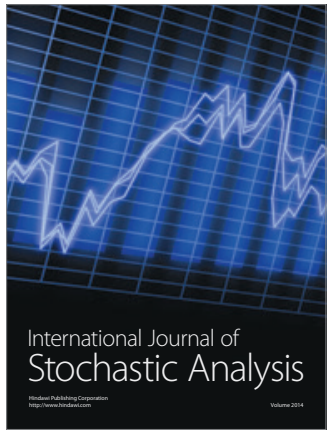

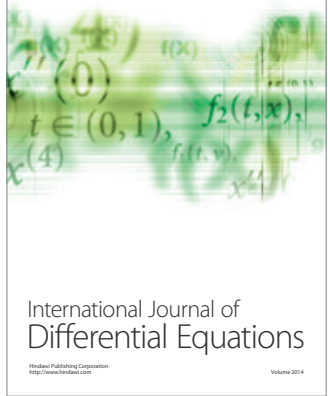
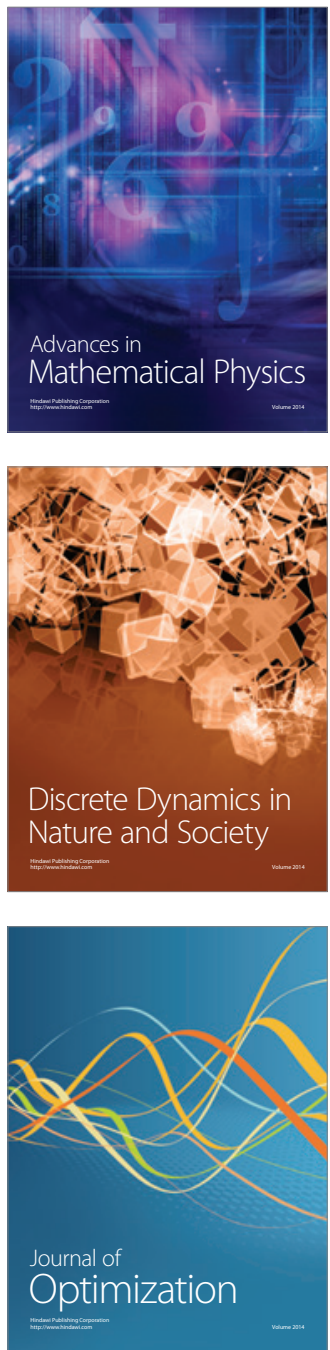